\title{
Utility of circulating tumor DNA in cancer diagnostics with emphasis on early detection
}

\author{
Clare Fiala ${ }^{1}$ and Eleftherios P. Diamandis ${ }^{1,2,3^{*}}$
}

\begin{abstract}
Various recent studies have focused on analyzing tumor genetic material released into the blood stream, known as circulating tumor DNA (ctDNA). Herein, we describe current research on the application of ctDNA to cancer management, including prognosis determination, monitoring for treatment efficacy/relapse, treatment selection, and quantification of tumor size and disease burden. Specifically, we examine the utility of ctDNA for early cancer diagnostics focusing on the development of a blood test to detect cancer in asymptomatic individuals by sequencing and analyzing mutations in ctDNA. Next, we discuss the prospect of using ctDNA to test for cancer, and present our calculations based on previously published empirical findings in cancer and prenatal diagnostics. We show that very early stage (asymptomatic) tumors are not likely to release enough ctDNA to be detectable in a typical blood draw of $10 \mathrm{~mL}$. Data are also presented showing that mutations in circulating free DNA can be found in healthy individuals and will likely be very difficult to distinguish from those associated with cancer.

We conclude that the ctDNA test, in addition to its high cost and complexity, will likely suffer from the same issues of low sensitivity and specificity as traditional biomarkers when applied to population screening and early (asymptomatic) cancer diagnosis.
\end{abstract}

Keywords: Circulating tumor DNA, Biomarker, Cancer diagnosis, Blood test, Early cancer detection, Cancer mutations, Translational omics

\section{Background}

Circulating tumor DNA (ctDNA) was first described in 1948 [1]. Following the technological advancements that enabled scientists to detect and sequence ctDNA in the blood, various studies and reviews on the utility of ctDNA in cancer have since emerged. The applications of ctDNA can be divided into five broad categories (Table 1), namely prognosis determination, monitoring of treatment and relapse detection, approximation of tumor size and burden, treatment selection, and detection of cancer in asymptomatic individuals. Herein, each category will be briefly discussed to provide the background context to our analysis of the technology required to develop a ctDNA blood test suitable for early cancer diagnosis.

\footnotetext{
* Correspondence: eleftherios.diamandis@sinaihealthsystem.ca

'Department of Pathology and Laboratory Medicine, Mount Sinai Hospital,

Toronto, ON, Canada

2Department of Laboratory Medicine and Pathobiology, University of

Toronto, Toronto, ON, Canada

Full list of author information is available at the end of the article
}

Using ctDNA to determine prognosis has shown promise across many different cancer types. Striking results were reported in a prospective study of 230 patients with early-stage colorectal cancer, wherein $100 \%$ of patients who had detectable ctDNA at the first follow-up visit after tumor resection surgery relapsed within 3 years compared to only $10 \%$ of the ctDNA-negative group [2]. Similar observations were reported in longitudinal studies of ctDNA concentrations in lung [3, 4], breast [5, 6], melanoma [7], and ovarian [8] cancers. Knowledge of prognosis can help the clinician make a more informed decision about the aggressiveness and scope of treatment. Additionally, it can aid in ensuring that patients who are more likely to relapse receive adjuvant therapy, while low-risk patients are spared unnecessary treatment [9].

Several investigations have demonstrated the utility of ctDNA monitoring for tumor resistance and treatment success. Traditional tumor biopsies cannot be performed

(c) The Author(s). 2018 Open Access This article is distributed under the terms of the Creative Commons Attribution 4.0 International License (http://creativecommons.org/licenses/by/4.0/), which permits unrestricted use, distribution, and reproduction in any medium, provided you give appropriate credit to the original author(s) and the source, provide a link to the Creative Commons license, and indicate if changes were made. The Creative Commons Public Domain Dedication waiver (http://creativecommons.org/publicdomain/zero/1.0/) applies to the data made available in this article, unless otherwise stated. 
Table 1 Applications of ctDNA in cancer diagnostics

\begin{tabular}{|c|c|c|}
\hline ctDNA Application & Summary & References \\
\hline Prognosis determination & $\begin{array}{l}\text { - Absence of ctDNA after surgery is associated with a much better prognosis and smaller } \\
\text { chances of relapse } \\
\text { - Prognosis determination aids in selecting aggressiveness of treatment as well as determining the } \\
\text { necessity for adjuvant therapy; patients at high risk of relapse could receive targeted treatment, } \\
\text { while low risk patients are spared unnecessary chemotherapy }\end{array}$ & {$[2-7,10,21,29]$} \\
\hline $\begin{array}{l}\text { Monitoring for treatment } \\
\text { efficacy/relapse }\end{array}$ & $\begin{array}{l}\text { - ctDNA can be analyzed through a blood test; this 'liquid biopsy' can be repeated more often, } \\
\text { enabling consistent monitoring of response to treatment } \\
\text { - Raised ctDNA concentrations or increased number of mutations indicate treatment failure/relapse } \\
\text { earlier than clinical relapse }\end{array}$ & {$[4,8-22,29]$} \\
\hline Selection of treatment & $\begin{array}{l}\text { - Sequencing the ctDNA informs choice of therapy to target specific mutations } \\
\text { - Traditional tumor biopsies only allow for the analysis of a certain part of the tumor, } \\
\text { which ignores } \\
\text { intratumor heterogeneity, while ctDNA analysis provides a more holistic view of the tumor } \\
\text { to inform more targeted treatment }\end{array}$ & {$[1,19-21,28]$} \\
\hline Tumor size/disease burden & $\begin{array}{l}\text { - Larger amount of ctDNA in blood correlates with advanced tumor stage/greater metastatic burden } \\
\text { - Blood testing does not carry the risk of radiation exposure or poor accuracy of imaging; ctDNA can } \\
\text { provide a snapshot of disease burden, which can be repeated more often than imaging or } \\
\text { traditional biopsies }\end{array}$ & {$[19,21,23,24,30]$} \\
\hline $\begin{array}{l}\text { Detection in asymptomatic } \\
\text { individuals }\end{array}$ & $\begin{array}{l}\text { - Most studies show poor sensitivity, especially for early stage tumors } \\
\text { - For small tumors, there is not enough ctDNA present to allow for an accurate test result } \\
\text { - However, reliable ctDNA tests for early diagnosis would allow for early intervention and } \\
\text { curative surgery and higher cure rates }\end{array}$ & {$[16,20,25,30,32-38]$} \\
\hline
\end{tabular}

often due to their invasiveness and discomfort, while frequent imaging carries the risk of repeated radiation exposure. However, considerable progress has been made in the technology to sequence and analyze ctDNA. These minimally invasive tests can be repeated frequently, providing constant updates of tumor genetic composition and mutations, and thus informing the best course of treatment [10-13]. Further, they also allow for better monitoring of intra-tumor heterogeneity [9]; unlike traditional biopsies, which only sequence a portion of the tumor, ctDNA provides an overview of all the mutations, allowing for a more targeted treatment. These 'liquid biopsies' are now gradually finding their way into the clinic, including FDA-approved EGFR mutation testing for therapy selection [14]. Studies monitoring patients during treatment have shown that lower ctDNA dynamics correlate with better treatment response in colorectal [15], ovarian [16], breast [5], non-small cell lung cancer (NSCLC) [17], and melanoma [18]. Other studies have indicated the potential of ctDNA in detecting resistance, even before its clinical manifestation [5]. For example, in patients with breast cancer, increases in ctDNA concentration provided the earliest indication of impending relapse compared with imaging and other blood-based cancer markers such as circulating tumor cells and cancer antigen 15-3 [5]. An increase in ctDNA was also shown to be more sensitive at screening for relapse than traditional biomarkers in melanoma and NSCLC $[19,20]$.

A recent investigation highlighting the utility of ctDNA screening for treatment response and resistance was published by Abbosh et al. [21]. In brief, this team sequenced and compared samples from tumor and healthy tissues from the primary surgical resection of patients with early NSCLC to identify the single nucleotide variants associated with cancer. Using this information, they created personalized ctDNA panels for 24 patients, designed to check for relapse by scanning the patients' blood for mutated ctDNA. These tests were able to detect relapse and resistance in patients 70 days, on average, before tumors became visible on computed tomography scans, with the lead time being over 6 months in four cases. In one patient in this study, sequencing of ctDNA revealed an amplification of the ERRB2 gene, a cancer promoter that can be targeted by existing chemotherapy medications [21]. Although this application is still being developed, it is proof of principle that ctDNA testing can lead to more personalized treatments. Similar results have also been observed in colorectal cancer, were chemotherapy resistance was shown through detection of resistance-related mutations in circulation months before progression became apparent with imaging $[22,23]$.

Higher levels of circulating free DNA (cfDNA) have also been associated with greater disease burden and number of metastatic sites $[16,24]$. An extensive study of 640 patients with a variety of types and stages of cancer found that the median concentration of ctDNA was 100 times higher in patients with stage IV disease compared to those with stage I disease, providing a basic proportion to estimate tumor size from ctDNA concentration [25]. In their study of early-stage NSCLC, Abbosh et al. [21] were able to develop a more exact metric to estimate tumor size, correlating a higher 
frequency of mutations in ctDNA or variant allele frequency with a greater tumor volume and finally associating a variant allele frequency measurement of $0.1 \%$ with a tumor volume of $10 \mathrm{~cm}^{3}$ (27 $\mathrm{mm}$ in diameter). Importantly, they also reported that a tumor volume of $10 \mathrm{~cm}^{3}$ was required for ideal sensitivity to their ctDNA tests, which is far larger than an early stage/asymptomatic tumor. This presents major sensitivity caveats in using ctDNA for detection in asymptomatic individuals where the tumors would be much smaller. Consequently, the current literature is not supportive of using ctDNA for the detection of small cancers in asymptomatic individuals. In lung cancer, ctDNA is not detectable in all patients with NSCLC $[17,26]$, showing that the cfDNA quantification/ sequencing method is currently limited for lung cancer diagnosis. Abbosh et al. [21] are in agreement with the above, clearly stating that their method is not suitable for asymptomatic early diagnosis. Table 1 summarizes the candidate future applications of ctDNA in the clinic.

Hundreds of millions of dollars have been invested in the lofty goal of developing a blood serum test to detect cancer in asymptomatic individuals. One company, GRAIL, has attracted US\$ 900 million in investment capital and accrued funding from Amazon, Johnson \& Johnson Innovation, Bill Gates, and Google as well as backing by an impressive number of leading scientists [27]. It is well established in the literature that early cancer detection significantly improves patient outcomes [28]. Thus, if successful, these blood tests will have a tremendous impact on the future of cancer detection and treatment. The tests will involve analysis of the minuscule amounts of cancerous genetic material released into the bloodstream by tumor cells [29]. As ctDNA is generally thought to have the same genetic composition as the tumor it was released from, including all its specific mutations, these tests could provide great insight into the tumor composition [10]. Some companies even hope to create a blood plasma test able to detect the minimal amounts of ctDNA released by asymptomatic or not yet imageable tumors. Detecting cancer at this early stage would mean that tumors would be very small, localized, and far less complex, enabling more effective treatment and a higher cure rate. Thus, in this article, we focus on the detection of very small tumors (less than $10 \mathrm{~mm}$ in diameter).

A review of the literature highlights that the utility of using ctDNA for early cancer detection is contested. Therefore, we herein explore, in some depth, the significant difficulties of this approach and the considerable hurdles to the development of a ctDNA blood test for cancer in asymptomatic individuals.

\section{Relevant calculations based on empirical evidence} ctDNA tests for early diagnosis involve the performance of ultra-deep sequencing of DNA fragments isolated from plasma/serum (liquid biopsy) to identify fragments that have mutations characteristic of malignant cells. These mutant fragments/mutations are considered as unique to malignancy and are not likely to be found in the plasma of normal individuals, which qualifies them as ideal tumor markers [10, 29]. Along with these mutated fragments, the plasma is expected to have otherwise identical, but non-mutated fragments, originating from normal tissues (cfDNA) [2]. Herein, for the sake of discussion, we have assumed that the sample contains a variable mixture of normal and mutant alleles and that the rate of release of these fragments in the circulation is mostly determined by the mass/volume of the tissues, irrespective of their malignant or normal status (Table 2). Similar calculations could be made using other hypothetical scenarios such as the fact that DNA release is 10 times more efficient from tumors compared to normal tissues. Furthermore, we roughly estimated the expected ratio of mutant to normal alleles based on empirical findings from the literature. To screen for a variety of cancers, the tests would need to simultaneously identify a large number (i.e., $50-500$ or more) of cancer-associated mutations in plasma. Thus, we assumed that the detection of one mutation would lead to $100 \%$ sensitivity and $100 \%$

Table 2 Assumptions made for cfDNA and ctDNA in patient plasma

\begin{tabular}{|c|c|c|}
\hline Assumption & Justification & References \\
\hline $\begin{array}{l}\text { Fetal DNA in maternal circulation is proportionally related to fetal } \\
\text { and maternal weight }\end{array}$ & $\begin{array}{l}\text { It has been documented that, as maternal weight } \\
\text { increases, the percent fetal DNA in maternal circulation } \\
\text { proportionally decreases }\end{array}$ & {$[32]$} \\
\hline $\begin{array}{l}\text { Circulating tumor DNA and circulating free DNA from normal tissues } \\
\text { diffuse into the circulation at roughly equal rates and by similar } \\
\text { mechanisms }\end{array}$ & $\begin{array}{l}\text { ctDNA and cfDNA levels are quite variable between } \\
\text { normal individuals and patients with cancer; however, } \\
\text { as tumor volume increases, the amount of ctDNA also } \\
\text { increases, correlating with tumor burden }\end{array}$ & {$[4,16,24,25,32,48]$} \\
\hline $\begin{array}{l}\text { In early cancer stages, the amount of ctDNA will not significantly } \\
\text { affect the amount of total cfDNA or the circulating genome } \\
\text { equivalents }\end{array}$ & $\begin{array}{l}\text { In early stage cancer, the amount of ctDNA is only } 0.1 \% \\
\text { or less, of total cfDNA; thus, it will not significantly } \\
\text { increase the number of circulating genomes }\end{array}$ & {$[10,17,26,38,39,42,43]$} \\
\hline $\begin{array}{l}\text { Tumors are spherical and their weight and cellularity are proportional } \\
\text { to the volume of the tumor; a tumor of } 1 \mathrm{~cm}^{3} \text { has a wet weight of } \\
1 \mathrm{~g} \text { and contains approximately } 10^{9} \text { cells }\end{array}$ & $\begin{array}{l}\text { Calculations are intended to be approximations in order to } \\
\text { estimate the ratio of tumor/normal DNA in the circulation } \\
\text { Abbosh et al. [21] reported that a } 10 \mathrm{~cm}^{3} \text { tumor leads to } \\
0.1 \% \text { ctDNA in the circulation (see text for greater detail) }\end{array}$ & {$[21,39,43]$} \\
\hline
\end{tabular}


specificity (the best-case scenario). Sensitivity and specificity are addressed further on.

In pregnancy, the presence of a foreign body (the fetus within the mother) is a good proxy of tumor presence. Fetal and maternal DNA are distinguishable based on abundance, single nucleotide variants, or epigenetic changes and these differences are now used for prenatal diagnosis of fetal defects such as aneuploidies and genetic diseases [30, 31]. In maternal serum screening programs, performed at approximately $10-20$ weeks' gestation, it has been shown that the amount of total fetal (placental) DNA in circulation is approximately $5-10 \%$ of the total DNA (90-95\% of which originates from the mother) [32]. The finding that the fetal DNA fraction (the percent of DNA coming from the fetus) is inversely related to maternal weight suggests that similar mechanisms operate during the release of maternal or fetal DNA in the maternal circulation [32], as assumed herein for cancer (Table 2). Considering a fetal/placental unit weight of approximately $0.5 \mathrm{~kg}$ at a gestational age of 20 weeks $(\sim 300 \mathrm{~g}$ for the fetus and $170 \mathrm{~g}$ for the placenta), the proportional percent DNA for a smaller fetus/placental unit can be roughly estimated by extrapolation (Table 3 ).

The reported amount of circulating DNA in normal individuals and patients with cancer varies widely, likely due to methodological differences and patient characteristics such as cancer stage, vascularization, degree of necrosis, apoptosis, etc. [25, 33]. The range of reported values varies by 1 to 2 orders of magnitude [34-37]; however, most studies cite amounts of cfDNA in normal individuals within the range $1-10 \mathrm{ng} / \mathrm{mL}$ (average $5 \mathrm{ng} / \mathrm{mL}$ ) $[10,38,39]$. Assuming a molecular mass of DNA of approximately $2 \times 10^{12}, 5 \mathrm{ng}$ of DNA equates to approximately 1500 genomes, which matches well with the amount of DNA previously reported (2400 genomes per $\mathrm{mL}$ of plasma in maternal circulation) (Table 3) [40, 41]. According to this data, when the fraction of fetal/cancer DNA drops below 0.01\% (one cancer genome admixed with 10,000 normal genomes), then the use of $10 \mathrm{~mL}$ of blood $(4 \mathrm{~mL}$ of plasma) will likely not contain a single fetal/cancer genome for sequencing, thus rendering the diagnosis of cancer impossible due to sampling error.

We also used other reported tumor measures to calculate the approximate amount of cancer or normal DNA in the circulation of patients with small tumors [42]. Table 4 summarizes our calculations, with the bold font indicating experimental data; the rest of the numbers were calculated by extrapolation assuming proportionality between tumor volume and percentage fraction of mutant DNA, as suggested by Abbosh et al. [21]. It is also well accepted that a tumor of approximately $1 \mathrm{~cm}^{3}$ in volume has a wet weight of $1 \mathrm{~g}$, contains $10^{9}$ cells [43], and has an approximate diameter of $1.2 \mathrm{~cm}$ (assuming a spherical nodule). It can be seen from this table that, when the fraction of tumor DNA drops below 0.01\% (one tumor DNA molecule admixed with 10,000 normal DNA molecules), then $10 \mathrm{~mL}$ of blood (4 mL of plasma) will likely contain less than one cancer genome, rendering diagnosis unlikely. Table 4 also shows the likelihood of progression of breast tumors, as reported by Narod [44], and the sensitivity of mammographic screening [45]. If we set an arbitrary clinical requirement of screening to detect cancers that are at least $6 \%$ likely to progress and are also now mostly missed by mammography, then a $5 \mathrm{~mm}$ diameter tumor would be a realistic and clinically relevant early detection goal. However, this goal is not likely to be met by the suggested ctDNA sequencing technology (Table 4). Other organizations, such as the Ontario Institute for Cancer Research, set goals for the detection of even smaller tumors (as small as $1 \mathrm{~mm}$ ) [46]. Nevertheless, such over-ambitious goals have to be balanced with the realities of current technologies to avoid over-diagnosis or incorrect results.

As the empirical data suggests, current methods could predictably detect tumors of between 1 and $3 \mathrm{~cm}$, which are usually at an early stage but frequently present with

Table 3 Ratio of fetal/maternal DNA in maternal circulation

\begin{tabular}{llllll}
\hline $\begin{array}{l}\text { Weight of fetus/ } \\
\text { placental unit }\end{array}$ & $\begin{array}{l}\text { Percentage fetal } \\
\text { DNA in maternal } \\
\text { plasma }\end{array}$ & $\begin{array}{l}\text { Ratio of fetal to } \\
\text { maternal DNA } \\
\text { in maternal circulation }\end{array}$ & $\begin{array}{l}\text { Whole fetal/cancer genome } \\
\text { equivalents per } 4 \mathrm{~mL} \text { of plasma }\end{array}$ & $\begin{array}{l}\text { Number of malignant cells } \\
\text { in tumor of this size }\end{array}$ & $\begin{array}{l}\text { Likelihood of successful } \\
\text { cancer detection }^{c}\end{array}$ \\
\hline $\mathbf{0 . 5} \mathbf{~ k g}$ & $\mathbf{1 0}$ & $\mathbf{1 : 1 0}$ & $\mathbf{1 0 0 0}$ & $\mathbf{1 0 ^ { \mathbf { 1 2 } }}$ & High \\
$100 \mathrm{~g}$ & 2 & $1: 50$ & 200 & $10^{11}$ & High \\
$10 \mathrm{~g}$ & 0.2 & $1: 500$ & 20 & $10^{10}$ & Moderate \\
$1 \mathrm{~g}^{\mathrm{d}}$ & 0.02 & $1: 5000$ & 2 & $10^{9}$ & Low \\
$100 \mathrm{mg}$ & 0.002 & $1: 50,000$ & $<1$ & $10^{8}$ & Very low \\
$10 \mathrm{mg}$ & 0.0002 & $1: 500,000$ & $<1$ & $10^{7}$ & Unlikely \\
$1 \mathrm{mg}$ & 0.00002 & $1: 5,000,000$ & $<1$ & $10^{6}$ & Unlikely \\
\hline
\end{tabular}

${ }^{\mathrm{a}}$ Bold numbers indicate experimental data

${ }^{b} 1 \mathrm{~mL}$ of blood contains approximately 2400 whole genome equivalents in pregnant women and normal individuals [40, 41]

cCalculated by extrapolation of data mentioned by Uvili et al. [34]

${ }^{d}$ These ranges have been reported as thresholds for successful detection of cancer based on ctDNA by the most sensitive techniques available to date [29, 60, 61] 
Table 4 Tumor characteristics reported in the literature or calculated by extrapolation

\begin{tabular}{|c|c|c|c|c|c|c|c|}
\hline $\begin{array}{l}\text { Tumor } \\
\text { diameter, mm }\end{array}$ & $\begin{array}{l}\text { Tumor } \\
\text { weight, mg }\end{array}$ & $\begin{array}{l}\text { Tumor } \\
\text { volume, } \mathrm{mL}\left(\mathrm{cm}^{3}\right)\end{array}$ & $\begin{array}{l}\text { Number of } \\
\text { cancer cells }\end{array}$ & $\begin{array}{l}\text { Percentage fraction } \\
\text { of mutant ctDNA }\end{array}$ & $\begin{array}{l}\text { Number of cancer genomes } \\
\text { per } 10 \mathrm{~mL} \text { of blood }\end{array}$ & $\begin{array}{l}\text { Chance of } \\
\text { progression }^{c}\end{array}$ & $\begin{array}{l}\text { Mammographic } \\
\text { screen sensitivity }^{\text {d }}\end{array}$ \\
\hline 27 & 10,000 & $10^{\mathrm{a}}$ & $10,000,000,000$ & 1:1000 & 6 & & \\
\hline 12.5 & 1000 & $1^{b}$ & $1,000,000,000$ & $1: 10,000$ & 0.6 & & \\
\hline 10 & 500 & 0.5 & $500,000,000$ & $1: 20,000$ & 0.3 & $50 \%$ & $91 \%$ \\
\hline 8 & 250 & 0.25 & $250,000,000$ & 1:40,000 & 0.15 & $25 \%$ & \\
\hline 6 & 125 & 0.12 & $125,000,000$ & $1: 80,000$ & $<0.1$ & & \\
\hline 5 & 62 & 0.06 & $62,000,000$ & $1: 160,000$ & $<0.1$ & $6 \%$ & $26 \%$ \\
\hline 4 & 31 & 0.03 & $32,000,000$ & $1: 320,000$ & $<0.1$ & & \\
\hline 3 & 16 & 0.015 & $16,000,000$ & $1: 640,000$ & $<0.1$ & & \\
\hline 2.4 & 8 & 0.007 & $8,000,000$ & $1: 1,300,000$ & $<0.1$ & & \\
\hline 2 & 4 & 0.0035 & $4,000,000$ & $1: 2,600,000$ & $<0.1$ & & \\
\hline 1.5 & 2 & 0.0017 & $2,000,000$ & 1:5,200,000 & $<0.1$ & & \\
\hline 1.1 & 1 & 0.0008 & $1,000,000$ & 1:10,000,000 & $<0.1$ & $0.05 \%$ & \\
\hline
\end{tabular}

${ }^{\mathrm{a}}$ As reported by Abbosh et al. [21]

${ }^{\mathrm{b}}$ As reported by Del Monte [43]

'As reported by Cohen et al. [64]

${ }^{\mathrm{d}}$ As reported by Erdi [67]

clinical signs and symptoms. Moreover, tumors of such size are now readily visible through imaging $[42,47]$.

It is important to underline that both of the modeling scenarios outlined above, using experimental data from pregnancy and NSCLC, predict very similar detectability, pointing to a fractional tumor DNA abundance of $0.01 \%$ or higher (Tables 3 and 4).

From the above calculations, it can be concluded that, if a patient has a tumor of $5 \mathrm{~mm}$ in diameter, which is considered as an early asymptomatic stage, localized, less likely to progress, and curable, then the ratio of tumor to normal DNA in the circulation will be lower than $1: 100,000$ (Table 4). If we assume that $1 \mathrm{~mL}$ of plasma from a healthy individual contains approximately 3000 whole genome equivalents $[39,40$, and our own calculations], then the total amount of whole genome equivalents in the whole blood circulation (approximately $3 \mathrm{~L}$ of plasma) will be 9,000,000 (3000 copies multiplied by $3000 \mathrm{~mL}$ ). Thus, in the whole circulation, only approximately one cancer genome will originate from a $1 \mathrm{~mm}$ diameter tumor, with the rest arising from normal tissues (Table 4). Consequently, even if an ultimately sensitive analytical platform able to identify single copies of DNA sequences is used, the likelihood of harvesting one tumor-released DNA fragment from a small (1-4 mm diameter) tumor through a blood draw of $10 \mathrm{~mL}$ will be extremely low or non-existent. This would be true even if the total number of genomes released in circulation were to be increased by 10 -fold in early cancer. In various cancers, the levels of circulating tumor DNA are higher than in healthy patients, yet, on average, only by 2- to 5-fold [4, 34, 48]; additionally, the differences are expected to be much smaller or non-existent in small and early-stage tumors. The likelihood of this method working consistently is further lowered if we assume the mutant sequence is only present in the sample once. More copies will lead to a more reliable/reproducible estimation.

\section{Diagnostic specificity and sensitivity issues}

In population screening programs that test asymptomatic individuals, the specificity of the test is of paramount importance, especially if the disease is rare (prevalence $<1: 1000$ ) such as in many forms of cancer. For example, if a disease is present in the screened population at a frequency of 1 in 4000 (close to the actual prevalence of ovarian and pancreatic cancer), a population of 100,000 will include 25 affected and 99,975 unaffected individuals. Even if we assume a test's sensitivity to be close to $100 \%$ (so that nearly all affected individuals are captured), a 99\% specificity will yield 1000 false positives, with a positive predictive value (PPV) of only $2 \%$. The PPV represents the likelihood of someone who tested positive for a disease actually having the disease. Even at $99.9 \%$ specificity, there will still be 100 false positives, yielding a PPV of only $20 \%$. False positive results may lead to undue additional invasive and/or highly expensive tests (Fig. 1). In addition to the specificity prerequisites, several other factors, such as tumor dynamics, influence the outcome of population screening programs, as we and others have previously discussed [49-51]. Screening programs are not very effective for tumors that proliferate quickly (such as invasive breast or pancreatic carcinoma) because patients who originally test negative may go on to test positive with disseminated (thus incurable) disease in the next 


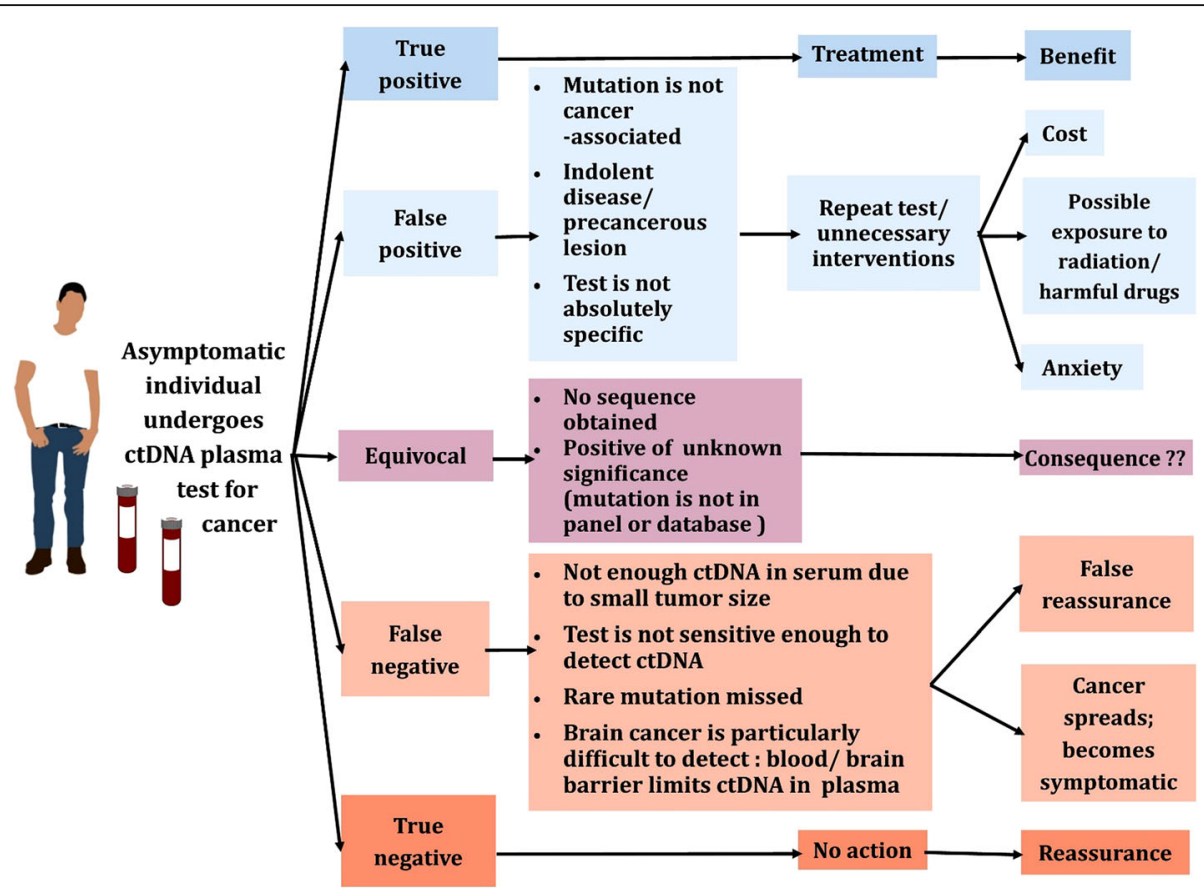

Fig. 1 Outcomes and consequences for an asymptomatic individual undergoing a blood serum test for cancer detection

round. On the other hand, slow-growing tumors, such as prostate cancer, may remain indolent for decades and detecting them in screening programs creates more harm than good through overdiagnosis [52]. It is also imperative for screening programs to prove that those who are screened actually receive tangible benefits such as prolonged disease-specific survival or overall survival.

We have speculated elsewhere that mutated DNA in the circulation may be an ideal tumor marker with superior performance in comparison to traditional biomarkers [53]. However, none of the traditional biomarkers are specific for tumor cells (as opposed to normal cells) since they represent overexpressed or fetal antigens or antigens leaking into the circulation, usually with no relation to tumor biology [54], and it may be incorrect to assume that non-diseased patients have no mutation in their serum/plasma, as recently demonstrated [55-60].

In an important study, Genovese et al. [55] sequenced the DNA of the peripheral blood cells of 12,380 individuals for mutations and followed their health outcomes for 2 to 7 years, arriving to some significant conclusions. Clonal hematopoiesis, namely the formation of a genetically distinct subset of blood cells, was observed in $10 \%$ of individuals aged over 65 years but in only $1 \%$ of those younger than 50 years. Their investigation revealed that approximately $42 \%$ of participants who received a diagnosis of cancer had detectable clonal hematopoiesis with somatic mutations at the time of blood sampling, at least 6 months prior to the first diagnosis. Finally, they found that a portion of some of the genes that are mutated in patients with myeloid cancers are also mutated in healthy individuals and therefore do not cause cancer [55]. Thus, mutations in circulating DNA are not necessary or sufficient for cancer development. This critical finding, namely that not all mutations lead to cancer, is also echoed by Alexandrov et al. [56] in their landmark paper about the mutational rate of clocklike somatic cells.

Furthermore, Schwaderle et al. [57] reported that, among 222 healthy volunteers, one had an alteration in the $p 53$ gene in cfDNA from plasma ( $\sim 5 \%$ frequency). Gormally et al. [58] reported mutations with a frequency of $1.2 \%$ for KRAS2 and 3.6\% of $p 53$ genes in plasma DNA from volunteers who were followed for over 6 years and remained cancer free. Fernandez-Cuesta et al. [59] reported an even higher frequency of $p 53$ mutations in cfDNA from normal controls $(\sim 11 \%)$. Mutations of $p 53$ in normal individuals were also reported by Newman et al. [60]. It is important to mention here that mutations in $p 53$ in normal cfDNA may be very difficult to overcome for a diagnostic cancer test since they are the most prevalent genetic alterations in many tumors and drive the sensitivity of such assays, as reported recently by Phallen et al. [61]. These data pose serious challenges for the development of a ctDNA-based screening test. In order to improve sensitivity, ctDNA-based tests must include panels of 100 or more genes, further predictably compromising specificity and reducing confidence of identification due to multiple hypotheses testing [10]. Furthermore, rare variants will likely still be missed in this wide-ranging screening process. 
Another new and important discovery is the concept of mosaicism in normal cells and healthy tissue [62]. Neurons have one of the longest lifespans among cells in the body and, as a result, they develop many somatic mutations. These mutations often develop in small populations of adjacent neurons, creating diverse neuronal genomes that are heterogeneous with other regions of the brain. It is increasingly thought that these mutations and cell populations influence neuronal development and function and contribute to various neurodevelopmental disorders. Thus, as the brain develops, subset regions harbor unique single nucleotide variations that are highly specific for a particular region but completely absent in other regions of the brain [62]. This new finding adds yet another challenge in the development of a highly specific cancer test. The Single Cell Sequencing project, which is ongoing, will likely uncover other caveats of individual cell DNA variations that may further complicate the development of a ctDNA blood test for early detection [63].

The most sensitive methods for detecting mutations in ctDNA in the presence of vast amounts of non-mutant DNA are based on the a priori knowledge of mutations that are first found in patient tumors gathered from resection or biopsy. However, in real case scenarios, such mutations will not be known, posing another stress to the assay's sensitivity. In this respect, Newman et al. [60] developed a highly sensitive assay for detecting mutations in ctDNA without the need for a biopsy. This deep sequencing approach, which incorporated integrated digital error suppression, was able to detect mutant DNA for the EGFR kinase domain admixed with 25,000-fold normal DNA. However, even at these cancer to normal ctDNA ratios, and as predicted in Tables 3 and 4, the likely weight of the detected tumors would be within the $100 \mathrm{mg}$ to $1 \mathrm{~g}$ range, well above what is likely needed to detect cancer in asymptomatic individuals.

\section{Latest results and conclusions}

Quality assurance in developing a test for cancer is of paramount importance due to the risk of over- or undertreatment following false positive or negative results, both of which are damaging to patients [51].

This analysis indicates that, apart from technical competence in identifying single nucleotide variations or other changes in circulating DNA, the assumed outstanding specificity of a test derived from these principles is not guaranteed. Even if it were, the value of screening to identify early and curable disease with the suggested method would still have to be assessed. We envision that it will take considerable time before the critical questions raised are answered by prospective studies. The expected outcomes and consequences of ctDNA testing for cancer diagnosis are further summarized in Fig. 1.
Theoretical and empirical findings support our conclusion that there is not enough ctDNA in the blood for a sufficiently accurate test result for early or asymptomatic diagnosis (Fig. 2). Additionally, not all mutations signify cancer. However, ongoing research may unveil previously unknown facts that could change our understanding of the advantages and limitations of using ctDNA testing in asymptomatic individuals.

Nevertheless, certain applications of ctDNA look promising (Table 1) such as utilizing it to predict prognosis, monitor treatment efficacy, and development of drug resistance in already diagnosed individuals $[10,21]$. Since these tumors are larger and their genetic information is already available from traditional tumor biopsies or resection, ctDNA tests in these situations are poised to provide higher specificity and sensitivity than traditional markers.

Furthermore, while ctDNA testing is being widely researched and developed, it remains very expensive. Abbosh et al. [21] estimated a cost of US\$ 1750 to create a personalized assay and perform the tests, yet their panel only targeted 12-30 single nucleotide variants and is significantly below what would be needed to provide a far more comprehensive, diagnostic test. The tests are also time consuming and require specialized skills and equipment; if these were to be performed on a clinical scale, samples would likely have to be shipped to a central location, with a delay in the order of weeks before clinicians could receive the results. In contrast, serum testing for traditional circulating protein markers (such as CEA and CYFRA 21-1 for NSCLC) is far simpler, costs only a few dollars per sample, and can be performed within a few hours. Therefore, in some circumstances classical tumor markers should be preferred, assuming they perform equally well, due to cost, speed, and quality assurance. More research is needed to compare the performance of these traditional biomarkers with that of ctDNA technology to ensure this more expensive technology provides additional information.

\section{Conclusion}

Based on current knowledge and available technologies, ctDNA could be harvested and analyzed to signify cancer only when the tumor weight is in the range of $100 \mathrm{mg}$ to $1 \mathrm{~g}$ or has an approximate diameter of $\geq$ $1 \mathrm{~cm}$. In such cases, the ratio of ctDNA to normal DNA is expected to be within the range of $1: 10,000$ to 1:100,000. These tumor sizes represent large enough tumors visible by imaging and which are less likely to be curative by radical surgery. Therefore, it would be preferable for the test to be at least 100 -fold more sensitive in order to detect tumors of $5 \mathrm{~mm}$ in diameter. The major limiting factor in achieving this detection sensitivity is sampling error due to limited blood availability. With such small tumors, the released ctDNA is unlikely 


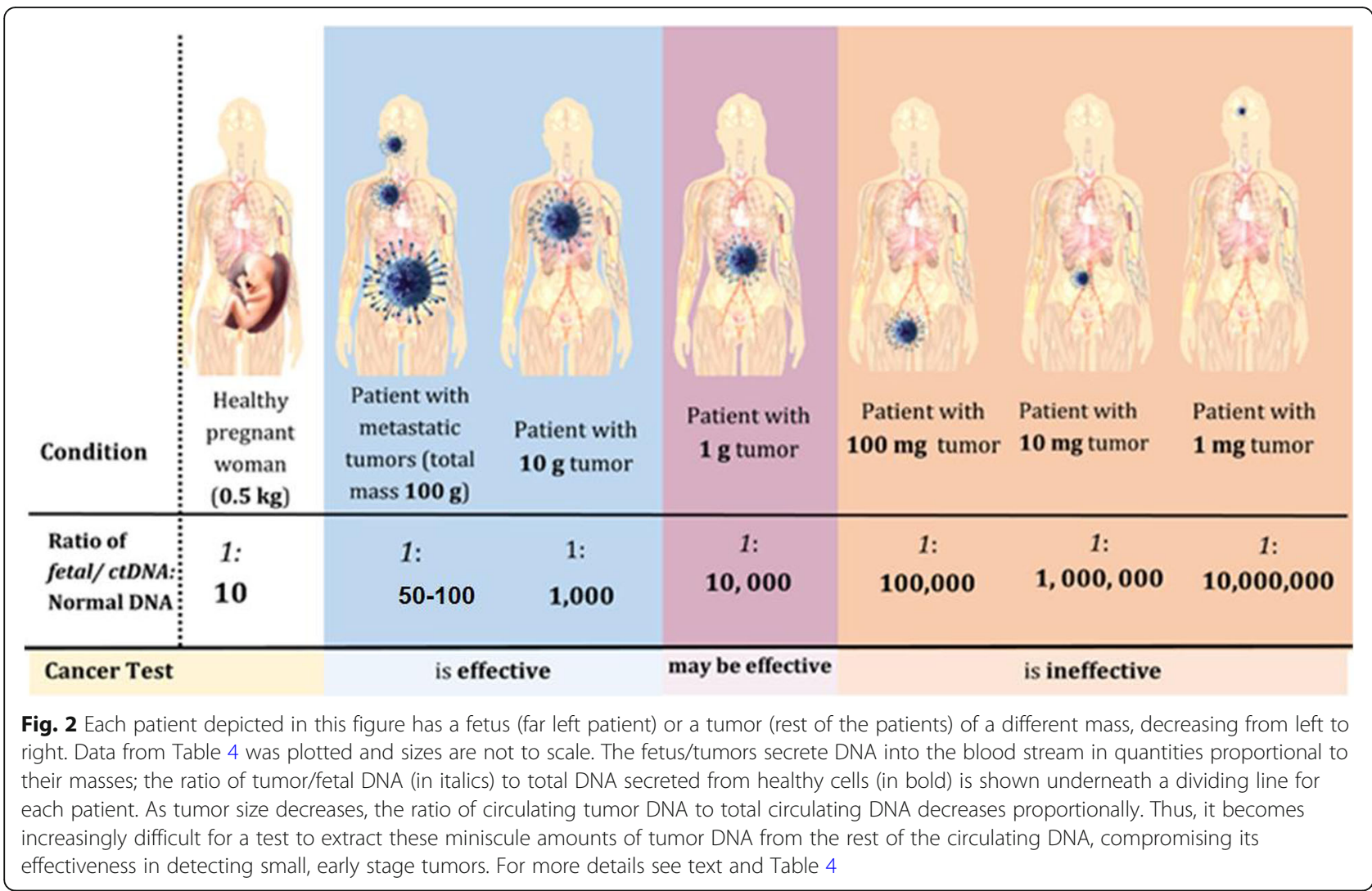

to be present even at a single copy in a $10 \mathrm{~mL}$ blood draw. Complicating the interpretation is the fact that recent data suggests that mutations in circulating DNA could be found in a significant proportion of normal individuals. In this respect, the new molecular tumor marker, ctDNA, may suffer from the same limitations of classical protein circulating markers, namely low sensitivity and specificity, especially for early detection.

Two very recent studies indirectly confirm our predictions. Phallen et al. [61] claimed early cancer detection with $70 \%$ sensitivity and $95 \%$ specificity based on ctDNA sequencing, yet all their samples contained more than $0.01 \%$ tumor DNA, as we discussed in our recent publication [43]. Additionally, Cohen et al. [64] recently reported a combination of circulating tumor markers and ctDNA for early detection of non-metastatic cancers of the ovary, liver, stomach, pancreas, esophagus, colorectum, lung, and breast cancer. The reported sensitivities ranged from 69 to $98 \%$ for ovarian, liver, stomach, pancreas, and esophageal cancer, at $>99 \%$ specificity [64]. However, all of their patients were symptomatic at diagnosis.

Recently, the biotechnology company GRAIL performed a highly relevant study, presented at the 2018 ASCO Annual Conference $[65,66]$, wherein they prospectively collected 1627 samples from 749 controls (no cancer) and 878 patients with newly diagnosed and untreated cancer (20 tumor types of all stages). The overall sensitivity of their blood ctDNA test was between 50 and $90 \%$ (stages I-III) but for some cancers (low Gleason grade prostate, thyroid, uterine, melanoma, and renal) the assay had less than $10 \%$ sensitivity. Specificity was fixed at 95\%. GRAIL claimed that their ctDNA-based blood test detected multiple cancers at various stages with good sensitivity and high specificity, thus being a new, promising multi-cancer screening test. In a separate breast cancer study [66], including 358 patients with invasive breast cancer (mostly stage I-II) and 452 controls, GRAIL also reported, for symptomatically diagnosed breast cancer patients, average sensitivity values of $58 \%, 40 \%$, and $15 \%$, respectively, in triple negative, HER2-positive/hormone receptor-positive, and HER2-negative breast cancer subtypes, at 95\% specificity. However, when patients were classified according to the mode of diagnosis (symptomatic versus screen-detected/asymptomatic), the sensitivities were $44 \%$ for symptomatic patients and only $10 \%$ for screened-detected/asymptomatic breast cancers.

These newly derived data from GRAIL fully support our notion that this method will be problematic in terms of both sensitivity and specificity for early cancer detection. Diagnostic effectiveness aside, it will also be necessary to address other important issues related to early cancer screening, including over-diagnosis and over-treatment [51]. Currently ongoing studies are expected to shed more light on this highly interesting area of cancer research. 


\section{Abbreviations}

cfDNA: circulating free DNA; ctDNA: circulating tumor DNA; NSCLC: non-small cell lung cancer; PPV: positive predictive value

\section{Authors' contributions}

Both authors contributed equally to the manuscript. Both authors read and approved the final manuscript.

\section{Ethics approval and consent to participate}

Not applicable.

\section{Consent for publication}

Not applicable.

\section{Competing interests}

EPD has an advisory role at Abbott Diagnostics. CF has no competing interests.

\section{Publisher's Note}

Springer Nature remains neutral with regard to jurisdictional claims in published maps and institutional affiliations.

\section{Author details}

'Department of Pathology and Laboratory Medicine, Mount Sinai Hospital, Toronto, ON, Canada. ${ }^{2}$ Department of Laboratory Medicine and Pathobiology, University of Toronto, Toronto, ON, Canada. ${ }^{3}$ Department of Clinical Biochemistry, Mount Sinai Hospital and University Health Network, 60 Murray St. Box 32, Floor 6, Rm L6-201, Toronto, ON MST 3L9, Canada.

\section{Received: 6 April 2018 Accepted: 17 August 2018}

Published online: 02 October 2018

\section{References}

1. Mandel P, Métais P. Les acides nucléiques du plasma sanguin chez I’homme. C R Séances Soc Biol. 1948;142:241-3.

2. Tie J, Wang J, Tomasetti C, et al. Circulating tumor DNA analysis detects minimal residual disease and predicts recurrence in patients with stage II colon cancer. Sci Transl Med. 2016;8:346ra92.

3. Nygaard AD, Holdgaard PC, Spindler KL, Pallisgaard N, Jakobsen A. The correlation between cell-free DNA and tumour burden was estimated by PET/CT in patients with advanced NSCLC. Br J Cancer. 2014;110:363-8.

4. Catarino R, Coelho A, Araújo A, et al. Circulating DNA: diagnostic tool and predictive marker for overall survival of NSCLC patients. PLoS One. 2012;7: e38559.

5. Dawson S-J, Tsui JW, Murtaza M, et al. Analysis of circulating tumor DNA to monitor metastatic breast cancer. N Engl J Med. 2013;368:1199-209.

6. Oshiro C, Kagara N, Naoi Y, et al. PIK3CA mutations in serum DNA are predictive of recurrence in primary breast cancer patients. Breast Cancer Res Treat. 2015;150:299-307.

7. Lipson EJ, Velculescu VE, Pritchard TS, et al. Circulating tumor DNA analysis as a real-time method for monitoring tumor burden in melanoma patient undergoing treatment with immune checkpoint blockade. J Immunother Cancer. 2014:2:42

8. Parkinson CA, Gale D, Piskorz AM, et al. Exploratory analysis of TP53 mutations in circulating tumour DNA as biomarkers of treatment response for patients with relapsed high-grade serous ovarian carcinoma: a retrospective study. PLoS Med. 2016;13:e1002198.

9. Popper HH. Commentary on tumor heterogeneity. Transl Lung Cancer Res. 2016:5:433-5.

10. Wan JCM, Massie C, Garcia-Corbacho J, et al. Liquid biopsies come of age: towards implementation of circulating tumour DNA. Nat Rev Cancer. 2017; 17:223-38.

11. Siravegna G, Marsoni S, Siena S, Bardelli A. Integrating liquid biopsies into the management of cancer. Nat Rev Clin Oncol. 2017;14:531-48.

12. Bardelli A, Pantel K. Liquid biopsies, what we do not know (yet). Cancer Cell. 2017:31:172-9.

13. Diaz LA Jr, Bardelli A. Liquid biopsies: genotyping circulating tumor DNA. J Clin Oncol. 2014:32:579-86.

14. Feng WN, Gu WQ, Zhao N, et al. Comparison of the SuperARMS and droplet digital PCR for detecting EGFR mutation in ctDNA from NSCLC patients. Transl Oncol. 2018;11:542-5.
15. Diehl F, Schmidt K, Choti MA, et al. Circulating mutant DNA to assess tumor dynamics. Nat Med. 2008;14:985-90.

16. Forshew T, Murtaza M, Parkinson C, et al. Non-invasive identification and monitoring of cancer mutations by targeted deep sequencing of plasma DNA. Sci Transl Med. 2012;4:136ra68.

17. Newman AM, Bratman SV, To J, et al. An ultrasensitive method for quantitating circulating tumor DNA with broad patient coverage. Nat Med. 2014;20:548-54.

18. Gray ES, Rizos H, Reid AL, et al. Circulating tumor DNA to monitor treatment response and detect acquired resistance in patients with metastatic melanoma. Oncotarget. 2015:6:42008-18.

19. Schreuer M, Meersseman G, Van Den Herrewegen S, et al. Quantitative assessment of BRAF V600 mutant circulating cell-free tumor DNA as a too for therapeutic monitoring in metastatic melanoma patients treated with BRAF/MEK inhibitors. J Transl Med. 2016;14:95.

20. Marchetti A, Palma J, Felicioni $L$, et al. Early prediction of response to tyrosine kinase inhibitors by quantification of EGFR mutations in plasma of NSCLC patients. J Thorac Oncol. 2015;10:1437-43.

21. Abbosh C, Birkbak NJ, Wilson GA, et al. Phylogenetic ctDNA analysis depicts early-stage lung cancer evolution. Nature. 2017;545:446-51.

22. Mohan $\mathrm{S}$, Heitzer $\mathrm{E}$, Ulz $\mathrm{P}$, et al. Changes in colorectal carcinoma genomes under anti-EGFR therapy identified by whole-genome plasma DNA sequencing. PLoS Genet. 2014;10:e1004271.

23. Misale $S$, Yaeger $R$, Hobor $S$, et al. Emergence of KRAS mutations and acquired resistance to anti-EGFR therapy in colorectal cancer. Nature. 2012; 486.532-6.

24. Yanagita M, Redig AJ, Paweletz CP, et al. A prospective evaluation of circulating tumor cells and cell-free DNA in EGFR-mutant non-small cell lung cancer patients treated with erlotinib on a phase II trial. Clin Cancer Res. 2016:22:6010-20.

25. Bettegowda C, Sausen M, Leary RJ, et al. Detection of circulating tumor DNA in early- and late-stage human malignancies. Sci Transl Med. 2014;6: $224 \mathrm{ra} 24$.

26. Villaflor V, Won B, Nagy R, et al. Biopsy-free circulating tumor DNA assay identifies actionable mutations in lung cancer. Oncotarget. 2016;7:66880-91.

27. GRAlL. https://grail.com/about/. Accessed 30 Mar 2018.

28. Etzioni R, Urban N, Ramsey S, et al. The case for early detection. Nat Rev Cancer 2003:3:243-52.

29. Aravanis AM, Lee M, Klausner RD. Next-generation sequencing of circulating tumor DNA for early cancer detection. Cell. 2017;168:571-4.

30. Chiu RW, Cantor CR, Lo YM. Non-invasive prenatal diagnosis by single molecule counting technologies. Trends Genet. 2009;25:324-31.

31. Chitty LS. Use of cell-free DNA to screen for Down's syndrome. N Engl J Med. 2015;372:1666-7.

32. Canick JA, Palomaki GE, Kloza EM, Lambert-Messerlian GM, Haddow JE. The impact of maternal plasma DNA fetal fraction on next generation sequencing tests for common fetal aneuploidies. Prenat Diagn. 2013:33: $667-74$

33. Leung F, Kulasingam V, Diamandis EP, et al. Circulating tumor DNA as a cancer biomarker: fact or fiction? Clin Chem. 2016;62:1054-60

34. Uvili P, Mercatali L, Casoni GL, et al. Multiple marker detection in peripheral blood for NSCLC diagnosis. PLoS One. 2013;2:e57401.

35. Warton K, Lin W, Navin T, et al. Methylation-capture and next-generation sequencing of free circulating DNA from human plasma. BMC Genomics. 2014:15:476

36. Breitbach S, Tug S, Simon P. Circulating cell-free DNA: an up-coming molecular marker in exercise physiology. Sports Med. 2012;42:565-86.

37. El Messaoudi S, Rolet F, Mouliere F, Thierry AR. Circulating cell free DNA: preanalytical considerations. Clin Chim Acta. 2013;424:222-30.

38. Mouliere F, El Messaoudi S, Pang D, Dritschillo A, Thierry AR. Multi-marker analysis of circulating cell-free DNA towards personalized medicine for colorectal cancer. Mol Oncol. 2014:8(5):927-41.

39. Mouliere F, Robert B, Arnau Peyrotte E, et al. High fragmentation characterizes tumor derived circulating DNA. PLoS One. 2011:6:e233418.

40. Manokhina I, Singh TH, Penaherrera MS, Robinson WP. Quantification of cellfree DNA in normal and complicated pregnancies: overcoming biological and technical issues. PLoS One. 2014;9:e101500.

41. Bischoff FZ, Lewis DE, Simpson لL. Cell-free fetal DNA in maternal blood: kinetics, source and structure. Human Reprod Update. 2004;11:59-67.

42. Aberle DR, Adams AM, et al. Reduced lung cancer mortality with low dose computed tomography screening. N Engl J Med. 2011;365:395-409. 
43. Del Monte U. Does the cell number $10^{9}$ still really fit one gram of tumor tissue? Cell Cycle. 2009;8:505-6.

44. Narod SA. Disappearing breast cancers. Curr Oncol. 2012;19:59-60.

45. Weedon-Fekjaer $\mathrm{H}$, Lindqvist $\mathrm{BH}$, Vatten $\sqcup$, Aalen $\mathrm{OO}$, Tretli S. Breast cancer tumor growth estimated through mammography screening data. Breast Cancer Res. 2008;10:R41.

46. Garber K. Ontario institute offers new model of cancer research. J Natl Cancer Inst. 2008;100:980-2.

47. Diamandis EP, Fiala C. Can circulating tumor DNA be used for direct and early stage cancer detection? F1000Res. 2017;6:2129.

48. Elshimali Y, Khaddour H, Sarkissyan M, Wu Y, Vadgama JV. The clinical utilization of circulating cell free DNA (CCFDNA) in blood of cancer patients. Int J Mol Sci. 2013;14:18925-58

49. Diaz LA Jr, Williams RT, Wu J, et al. The molecular evolution of acquired resistance to targeted EGFR blockade in colorectal cancers. Nature. 2012; 486:537-40.

50. Diamandis EP. Cancer dynamics and the success of cancer screening programs. Clin Chem Lab Med. 2016;54:e211-2.

51. Diamandis EP, Li M. The side effects of translational omics: overtesting, overdiagnosis, overtreatment. Clin Chem Lab Med. 2016;54:389-96.

52. Esserman $L$, Shieh $Y$, Thompson I. Rethinking screening for breast cancer and prostrate cancer. JAMA. 2009:302:1685-92.

53. Diamandis EP. Present and future of cancer biomarkers. Clin Chem Lab Med. 2014:52:791-4.

54. Diamandis EP. Prostate-specific antigen: a cancer fighter and a valuable messenger? Clin Chem. 2000;46:896-900.

55. Genovese G, Kahler AK, Handsaker RE, et al. Clonal hematopoiesis and blood-cancer risk inferred from blood DNA sequence. N Engl J Med. 2014; 371:2477-87.

56. Alexandrov $\mathrm{L}$, Jones PH, Wedge DC, et al. Clocklike mutational processes in human somatic cells. Nat Genet. 2015:47:1402-7.

57. Schwaderle MC, Husain W, Fanta PT, et al. Detection rate of actionable mutations in diverse cancers using a biopsy-free (blood) circulating tumor DNA assay. Oncotarget. 2015;33:11004.

58. Gormally E, Vineis P, Matullo G, et al. TP53 and KRAS2 mutations in plasma DNA of healthy subjects and subsequent cancer occurrence: a prospective study. Cancer Res. 2006;66:6871-6.

59. Fernandez-Cuesta L, Perdomo S, Avogbe PH, et al. Identification of circulating tumor DNA for the early detection of small-cell lung cancer. eBioMedicine. 2016;10:6-12.

60. Newman AM, Lovejoy AF, Klass DM, et al. Integrated digital error suppression for improved detection of circulating tumor DNA. Nat Biotechnol. 2016;34:547-55.

61. Phallen J, Sausen M, Adleff $V$, et al. direct detection of early-stage cancer using circulating tumor DNA. Sci Transl Med. 2017;9:eaan2415.

62. McConnell MJ, Moran JV, Abyzov A, et al. Intersection of diverse neuronal genomes and neuropsychiatric disease: The Brain Somatic Mosaicism Network. Science. 2017;356:eaal1641.

63. Stubbington MJT, Rozenblatt-Rosen O, Regev A, Teichmann SA. Single cell transcriptomics to explore the immune system in health and disease. Science. 2017;358:58-63.

64. Cohen JD, Li L, Wang Y, et al. Detection and localization of surgically resectable cancers with a multi-analyte blood test. Science. 2018;

65. Liu MC, Maddala T, Aravanis A, et al. Breast cancer cell-free DNA (cfDNA) profiles reflect underlying tumor biology: The Circulating Cell-Free Genome Atlas (CCGA) study. J Clin Oncol. 2018;36:Suppl abstr 536.

66. Klein EA, Hubbel E, Maddala T, et al. Development of a comprehensive cellfree DNA (cfDNA) assay for early detection of multiple tumor types: The Circulating Cell-free Genome Atlas (CCGA) study. J Clin Oncol. 2018;36:Suppl abstr 12021

67. Erdi YE. Limits of tumor detectability in nuclear medicine and PET. Mol Imaging Radionucl Ther. 2012;21:23-8.

Ready to submit your research? Choose BMC and benefit from:

- fast, convenient online submission

- thorough peer review by experienced researchers in your field

- rapid publication on acceptance

- support for research data, including large and complex data types

- gold Open Access which fosters wider collaboration and increased citations

- maximum visibility for your research: over $100 \mathrm{M}$ website views per year

At BMC, research is always in progress.

Learn more biomedcentral.com/submissions 